\title{
HUBUNGAN POLA MAKAN DENGAN KEJADIAN DISPEPSIA
}

\author{
${ }^{1}$ SUMARNI, DINA ANDRIANI ${ }^{2}$ \\ 1,2 SEKOLAH TINGGI ILMU KESEHATAN NURUL HASANAH KUTACANE \\ Jl. Ahmad Yani, Pulo Kemiri Kecamatan Babussalam \\ Kutacane, Kabupaten Aceh Tenggara Provinsi Aceh \\ e-mail : lestarisumar@gmail.com
}

DOI : https://doi.org/10.35451/jkf.v2i1.282

\begin{abstract}
In the life of the general public, dispepsia is often equated with heartburn, because there are similarities in symptoms between the two. This assumption is actually not quite right, because the word ulcer comes from Dutch, which means stomach, while the word dispepsia comes from Greek, which consists of two words namely "dys" which means bad and "peptei" which means digestion. So dispepsia means poor digestion. This type of research is descriptive correlational using cross sectional approach. This research was conducted in the working area of the Biak Muli Health Center, Bambel District, Southeast Aceh Regency. in determining the sample the author uses accidental sampling technique that is taking samples that happen to come when researchers conduct data collection. During the research process, 31 samples were obtained. The results of the analysis of the results of data analysis using the chi-square test $\left(x^{2}\right)$ at a significance of $95 \%(a 0,05)$ with the help of SPSS, the Pearson chi-square sig value was obtained. is equal to $p$ $=0,008$. This test can be seen that the $p$ value $(0,008)$ obtained is smaller than $a(0,05)$. then it can be seen that there is a relationship between eating patterns with the incidence of dispepsia in the work area of Biak Muli Health Center, Bambel District, Southeast Aceh Regency in 2019. For health services to prioritize health education programs for rural communities with material about eating patterns and dyspeptic events.
\end{abstract}

Keywords : Dietary Habit, Incidence of Dispepsia

\section{Pendahuluan}

Penyakit dispepsia adalah suatu kondisi medis yang ditandai dengan nyeri atau rasa tidak nyaman pada perut bagian atas atau ulu hati (Irianto, 2015) dalam Fithriyana (2018). Dispepsia juga merupakan salah satu masalah kesehatan yang sangat sering ditemui dalam kehidupan sehari-hari keluhan kesehatan yang berhubungan dengan makan atau keluhan yang berhubungan dengan gangguan saluran cerna (Pardiansyah dan Yusran, 2016). Octaviana dan Anam (2018) juga menegaskan, dispepsia termasuk salah satu jenis penyakit yang tidak menular namun akibat paparan penyakit tersebut dapat menyebabkan mortalitas yang sangat tinggi. Penderita dispepsia biasanya terjadi tidak hanya di Indonesia, tetapi juga terjadi di seluruh Dunia.

Di dalam kehidupan masyarakat umum, penyakit dispepsia sering disamakan dengan penyakit maag, dikarenakan terdapat kesamaan gejala antara keduanya. asumsi ini sebenarnya kurang tepat, karena kata maag berasal dari bahasa Belanda, yang berarti lambung, sedangkan kata dispepsia 
berasal dari bahasa Yunani, yang terdiri dari dua kata yaitu "dys" yang berarti buruk dan "peptei " yang berarti pencernaan. Jadi dispepsia berarti pencernaan yang buruk (Fithriyana, 2018). Menurut Arsyad dkk (2018), ada beberapa gejala penyakit dispepsia yaitu seperti nyeri epigastrik, rasa penuh pada bagian epigastrik, dan perut terasa penuh saat makan (cepat kenyang), mual dan muntah.

Menurut Octaviana dan Anam (2018), penyakit dispepsia ini termasuk salah satu penyakit yang paling umum di temukan. WHO (2015) menemukan bahwa, ternyata kasus dispepsia di dunia mencapai $13-40 \%$ dari total populasi dalam setiap Negara. Hasil studi tersebut menunjukkan bahwa di Eropa, Amerika Serikat dan Oseania, prevalensi dispepsia sangat bervariasi antara 5-43\%.

Octaviana dan Anam (2018) memprediksikan bahwa, apabila tidak ditangani dengan serius maka pada Tahun 2020 proporsi angka kematian akibat penyakit tidak menular seperti dispepsia akan terus meningkat menjadi $73 \%$ dan proporsi kesakitan menjadi $60 \%$ di dunia. Sedangkan untuk negara SEARO (South East Asian Regional Office) pada Tahun 2020 diprediksi bahwa, angka kematian dan kesakitan karena penyakit tidak menular akan meningkat menjadi $42 \%-50 \%$.

Kasus dispepsia di kota-kota besar di Indonesia cukup tinggi. Dari penelitian yang dilakukan oleh Departemen Kesehatan RI Tahun 2015, angka kejadian dispepsia di Surabaya 31,2 \%, Denpasar $46 \%$, Jakarta $50 \%$, Bandung $32,5 \%$, Palembang 35,5 \%, Pontianak 31,2 \%, Medan 9,6 \% dan termasuk Aceh mencapai 31,7 \%. (Depkes RI, 2015).

Selanjutnya, data yang diperoleh dari Departemen Kesehatan RI Tahun 2015 juga ditemukan angka kejadian dispepsia di Aceh Besar 21,8\%, Sabang 24,9 \%, Aceh Utara 43.2\%, Bireun 35,5\%, Aceh
Selatan 41,7 \%, Langsa 41,2 \% dan Aceh Tenggara 32,5 \%. (Depkes RI, 2015). Sementara data yang diperoleh dari Dinas Kesehaten Aceh Tahun 2016, angka kejadian dispepsia di Aceh Tenggara meningkat menjadi $40 \%$ dimana angka tersebut paling banyak di Babussalam $15 \%$, dan selanjutnya Kecamatan Bambel 10\%, dan Lawe Alas $5 \%$ dan Lawe Sigala-Gala 5\% (Dinkes Aceh, 2016).

Menurut Sorongan dkk (2013), Penyebab timbulnya dispepsia adalah faktor diet dan lingkungan, sekresi cairan asam lambung, fungsi motorik lambung, persepsi visceral lambung, psikologi, dan infeksi Helicobacter pylori. Disamping itu, hasil pengamatan Soewadji (2012) menemukan bahwa, jeda antara jadwal makan yang lama dan ketidak teraturan makan ternyata sangat erat kaitannya dengan timbulnya gejala dispepsia atau dengan kata lain pola makan yang tidak teratur dapat menyebabkan dispepsia. Pola makan yang tidak teratur umunya menjadi masalah yang sering timbul pada remaja perempuan. Aktivitas yang tinggi baik kegiatan disekolah maupun di luar sekolah menyebabkan makan menjadi tidak teratur.

Hasil survei awal yang dilakukan pada Tanggal 14 Januari 2019 sampai dengan Tanggal 24 April Tahun 2019 yang dilakukan di Puskesmas Biak Muli Kecamatan Bambel Kabupaten Aceh Tenggara telah diperoleh data tentang penderita dispepsia sebanyak 217 orang yang terdiri dari 157 orang perempuan dan 60 orang laki-laki. Tingginya angka kejadian dispepsia yang diperoleh dari Puskesmas tersebut di atas tentunya ada faktor penyebabya.

\section{METOde PENELITIAN}

Jenis penelitian ini adalah deskriptif korelasional dengan menggunakan pendekatan cross sectional. Penelitian ini dilakukan di wilayah kerja Puskesmas Biak Muli Kecamatan Bambel Kabupaten 
Aceh Tenggara. dalam penentuan sampel penulis menggunakan teknik accidental sampling yaitu mengambil sampel yang kebetulan datang ketika peneliti melakukan pengumpulan data. Selama proses penelitian, sampel penelitian diperoleh sampel sebanyak 31 orang.

\section{HASIL PENELITIAN}

1). Analisis Univariat

Tabel 1. DistribusiFrekuensi Karakteristik Responden Berdasarkan Umur

\begin{tabular}{cccc}
\hline No. & Umur & $\mathrm{f}$ & $\%$ \\
\hline 1 & $16-25$ & 11 & 35,5 \\
2 & $26-35$ & 7 & 22,6 \\
3 & $36-45$ & 8 & 25,8 \\
4 & $46-55$ & 5 & 16,1 \\
\hline Total & & 31 & 100 \\
\hline
\end{tabular}

Berdasarkan hasil penelitian tentang distribusi frekuensi umur responden yang tercantum pada tabel 1 . di atas dapat diketahui bahwa, dari total 31 responden penelitian ternyata responden yang berumur 16-25 tahun berjumlah 11 orang $(35,5 \%)$, selanjutnya responden yang berumur 26-35 tahun berjumlah 7 orang $(22,6 \%)$, responden yang berumur 36-45 tahun berjumlah 8 orang $(25,8 \%)$ dan responden yang berumur 46-55 tahun berjumlah 5 orang $(16,1$ $\%)$.

Tabel 2

Distribusi

Frekuensi

Karakteristik Responden Berdasarkan Jenis Kelamin

\begin{tabular}{cccc}
\hline No. & $\begin{array}{c}\text { Jenis } \\
\text { Kelamin }\end{array}$ & $\mathrm{f}$ & $\%$ \\
\hline 1 & Perempuan & 23 & 74,2 \\
2 & Laki-Laki & 8 & 25,8 \\
\hline \multicolumn{2}{l}{ Total } & 31 & 100 \\
\hline
\end{tabular}

Berdasarkan hasil penelitian tentang frekuensi jenis kelamin responden yang tercantum pada tabel 2 . di atas dapat diketahui bahwa, dari total 31 responden penelitian ternyata responden yang berjenis kelamin perempuan berjumlah 23 orang $(74,2 \%)$. Sementara responden yang berjenis kelamin laki-laki hanya berjumlah 8 orang (25,8\%). Jadi, jika dilihat dari perbedaan jenis kelamin tersebut maka dapat diketahui bahwa, responden yang berjenis kelamin perempuan lebih dominan dibandiangkan dengan laki-laki.

Tabel 3. Distribusi Frekuensi Karakteristik Responden Berdasarkan Pekerjaan

\begin{tabular}{clcc}
\hline No. & Pekerjaan & $\mathrm{f}$ & $\%$ \\
\hline 1 & Petani & 21 & 67,7 \\
2 & PNS & 4 & 12,9 \\
3 & Pelajar/ & 6 & 19,4 \\
\hline \multicolumn{2}{c}{ Total } & 31 & 100 \\
\hline \multicolumn{2}{c}{ Berdasarkan hasil penelitian tentang }
\end{tabular}

distribusi frekuensi pekerjaan responden yang tercantum pada tabel 3 . di atas dapat diketahui bahwa, dari total 31 responden penelitian ternyata responden yang bekerja sebagai petani berjumlah 21 orang $(67,7 \%)$. Sementara responden yang bekerja sebagai Pegawai Negeri Sipil (PNS) berjumlah 4 orang $(12,9 \%)$ dan responden yang masih berstatus pelajar ataupun mahasiswa berjumlah 6 orang (19\%).

Tabel 4. Distribusi Frekuensi Pola Makan Responden

\begin{tabular}{cccc}
\hline No. & $\begin{array}{c}\text { Pola } \\
\text { Makan }\end{array}$ & $\mathrm{f}$ & $\%$ \\
\hline 1 & Tidak & 27 & 87,1 \\
2 & teratur & 4 & 12,9 \\
\hline \multicolumn{2}{c}{ Teratur } & 31 & 100 \\
\hline \multicolumn{2}{c}{ Berdasarkan hasil } & penelitian & tentang
\end{tabular}
distribusi frekuensi pola makan responden yang tercantum pada tabel 4 . di atas dapat diketahui bahwa, dari total 31 responden penelitian ternyata responden yang pola makannya tidak teratur berjumlah 27 orang $(87,1 \%)$. Sementara responden yang pola makannya teratur hanya berjumlah 4 orang $(12,9 \%)$.

Tabel $5 . \quad$ Distribusi

Frekuensi Kejadian Dispepsia

\begin{tabular}{clcc}
\hline No. & $\begin{array}{l}\text { Kejadian } \\
\text { Dispepsia }\end{array}$ & $\mathrm{f}$ & $\%$ \\
\hline 1 & Iya & 30 & 96,8 \\
2 & Tidak & 1 & 3,2 \\
\hline \multicolumn{2}{l}{ Total } & 31 & 100 \\
\hline
\end{tabular}


Berdasarkan hasil penelitian tentang distribusi frekuensi kejadian dispepsia yang tercantum pada tabel 5 . di atas dapat diketahui bahwa, dari total 31 responden penelitian ternyata responden yang mengalami kejadian dispepsia berjumlah 30 orang $(96,8 \%)$. Sementara responden yang tidak mengalami kejadian dispepsia hanya berjumlah 1 orang $(3,2 \%)$.

2). Analisis Bivariat

Tabel 6. Tabulasi Hubungan Pola Makan Dengan Kejadian Dispepsia

\begin{tabular}{|c|c|c|c|c|}
\hline \multirow[t]{2}{*}{ No. } & \multirow[t]{2}{*}{$\begin{array}{l}\text { Pola } \\
\text { Makan }\end{array}$} & \multicolumn{2}{|c|}{$\begin{array}{l}\text { Kejadian } \\
\text { Dispepsia }\end{array}$} & \multirow[t]{2}{*}{$\begin{array}{c}\text { Pearson } \\
\text { Chi- } \\
\text { Square }\end{array}$} \\
\hline & & $f$ & $\%$ & \\
\hline 1 & Teratur & 4 & $12,9 \%$ & \multirow{3}{*}{0.008} \\
\hline 2 & $\begin{array}{l}\text { Tidak } \\
\text { Teratur }\end{array}$ & 27 & $87,1 \%$ & \\
\hline Tota & & 31 & 100 & \\
\hline
\end{tabular}

Berdasarkan hasil penelitian pada tabel 6 . di atas menunjukkan bahwa, dari 31 responden terdapat 4 orang $(12,9 \%)$ dengan pola makan teratur mengalami kejadian dispepsia sedangkan sebanyak 27 orang $(87,1 \%)$. Kemudian, jika dilihat dari hasil analisis data dengan menggunakan uji chi-square $\left(x^{2}\right)$ pada kemaknaan $95 \% \quad(a \quad 0,05)$ dengan bantuan SPSS, maka diperoleh nilai Pearson Chi-Square adalah sebesar 0,008 . Berdasarkan hasil Pengujian dapat dilihat bahwa nilai $p(0,008)$ yang diperoleh lebih kecil dari $a(0,05)$. Dari hasil penelitian ini maka dapat disimpulkan bahwa ada hubungan antara pola makan dengan kejadian dispepsia.

\section{PEMBAHASAN}

1) Distribusi Frekuensi Responden Berdasarkan Umur, Jenis Kelamin Dan Pekerjaan

Berdasarkan hasil penelitian menunjukkan bahwa umur responden pada penelitian ini mayoritas masih tergolong muda yaitu antara 16-25 tahun yaitu sebanyak 35,5\%. Pada umur yang relatif muda ini merupakan waktu yang sangat rentan akan timbulnya berbagai macam penyakit salah satunya adalah kejadian dispepsia. Bahkan, pada umur seperti ini juga meruakan waktu yang sangat tepat mendeteksi mendeteksi lebih dini tentang kejadian dispepsia.
Hasil penelitian ini diperkuat oleh pengamatan Jones dkk (1989) dalam Sorongan (2013) bahwa, keluhan dispepsia banyak di dapatkan pada usia yang lebih muda yaitu mencapai $38 \%$.

Menurut Muya dkk (2015), walaupun kejadian dispepsia sangat rentan pada usia muda apabila tidak ditangani dengan serius maka seiring bertambahnya usia seseorang maka akan terus mengalami kejadian penyakit tersebut. Muya dkk (2015) kembali menjelaskan bahwa, pertambahan umur seseorang biasanya selalu berkaitan dengan penurunan aktivitas olahraga rutin dan penurunan aktivitas hormonal fisiologis seseorang sehingga sangat berhubungan dengan meningkatnya resiko kejadian dispepsia. Oleh karena itu, untuk menghindari kejadian dispepsia pada pada usia muda maka yang harus dilakukan yaitu dengan menjaga gaya hidup yang lebih baik.

Pada jenis kelamin memperlihatkan bahwa dari 31 reponden penelitian ternyata mayoritas responden berjenis kelamin perempuan dengan jumlah $74.2 \%$ sementara laki-laki hanya $25.8 \%$. Hasil penelitian ini sesuai dengan hasil penelitian yang dilakukan oleh Tiana dkk (2017) pada mahasiswa Fakultas Kedokteran Universitas Kristen Krida Wancana Angkatan 2013, ditemukan bahwa bahwa sindroma dispepsia mayorotas diderita oleh perempuan. Perbandingan insiden ini mencapai $2: 1$. Dari hasil penelitian ini menunjukkan bahwa perempuan mempunyai peluang yang lebih besar mengalami kejadian dispepsia dibandingkan laki-laki. Hasil penelitian ini kembali diperkuat oleh penelitian Tiana dkk (2017) yang bahwa, terdapat hubungan yang bermakna antara jenis kelamin dengan kejadian sindroma dispepsia fungsional karena diperoleh nilai $p<0,001$.

Salah satu penyebab kaum perempuan lebih dominan mengalami kejadan dispepsia adalah akibat faktor diet yang tidak tepat. Perempuan yang melakukan program diet yang tidak tepat tentunya akan sangat berbahaya dan tidak dianjurkan karena sangat beresiko mengalami kejadian penyakit yang behubungan dengan gangguan pada usus. Hal ini dudukung oleh pendapat Irwan (2015) yang menyatakan bahwa 
salah satu faktor menyababkan kejadian dispepsia pada perempuan adalah faktor diet. Oleh karena itu, untuk menghindari resiko kejadian dispepsia maka terutama kaum perempuan harus mengatur gaya hidup dengan baik.

Dilihat dari hasil penelitian tentang distribusi frekuensi responden berdasarkan pekerjaan dapat diketahui bahwa, responden penelitian yang paling dominan adalah bekerja sebagai petani yaitu $68 \%$. Pada hasil penelitian ini petani memang lebih dominan sebagai responden penelitian ini, karena secara umum disekitar lokasi penelitian mayoritas masyarakatnya berprofesi sebagai petani dan hanya sebagian kecil memiliki berprofesi lain. Sehingga pasien yang berobat ke lokasi penelitian ini ratarata petani.

2) Hubungan Pola Makan Dengan Kejadian Dispepsia

Hasil uji hipotesis dengan menggunakan uji chi-square $\left(x^{2}\right)$ pada kemaknaan 95\% $(a 0,05)$ bantuan SPSS, diperoleh nilai $p=0,008$. Pengujian ini dapat dilihat bahwa nilai $p(0,008)$ yang diperoleh, lebih kecil dari $a(0,05)$ ini menjelaskan bahwa terjadi penolakan terhadap $\mathrm{Ho}$ atau $\mathrm{Ha}$ di terima berarti ada hubungan pola makan dengan kejadian dispepsia Di Wilayah Kerja Puskesmas Biak Muli Kecamatan Bambel Kabupaten Aceh Tenggara Tahun 2019. Hasil penelitian ini sesuai dengan penelitian Tiana dkk (2017) yang mengatakan bahwa, terdapat hubungan yang bermakna antara pola makan dengan sindrom dispepsia. Menurut Tiana dkk (2017), Sindrom dispepsia adalah kumpulan gejala yang terdiri atas nyeri ulu hati, mual, kembung, muntah, rasa cepat kenyang, dan sendawa. Kejadian dispepsia ini memang sangat erat hubungannya dengan pola makan yang tidak teratur. Fithriyana (2018) juga menambahkan bahwa, kejadian dispepsia ini dapat disebabkan oleh kurangnya pemahaman seseorang tentang pola makan atau pun pola konsumsi makanan serta perilaku sehari-hari yang tidak terkontrol.

Menurut Andre dkk (2013), ketidak teraturan makan seperti kebiasaan makan yang buruk, tergesa-gesa, dan jadwal yang tidak teratur dapat menyebabkan dispepsia. Disamping itu, menurut Fithriyana (2018), munculnya resiko kejadian dispepsia pada seseorang akibat pola makan yang tidak baik seperti halnya kebiasaan kerlebihan memakan makanan pedas, asam, minum teh, kopi, dan minuman berkarbonasi. Menurut Putri dkk (2015) kebiasaan pola makan yang tidak baik ini mungkin dipengaruhi oleh faktor lingkungan tempat tinggal dan budaya.

Menurut asumsi peneliti bahwa kejadian dispepsia akan terus beresiko pada penderitanya apabila tidak ditangani dengan serius. Salah satu cara penanganannya tentunya dengan menerapkan pola makan yang benar dan sehat. Pola makan yang benar dan sehat yaitu pola makan yang teratur setiap harinya, mengkonsumsi makanan tidak berlebihan dan makan tepat waktu dengan jam yang sama setiap harinya dan mengurangi makanan yang mengandung bahan pengawet.

\section{KESIMPULAN}

Hasil analisis hasil analisis data dengan menggunakan uji chi-square $\left(x^{2}\right)$ pada kemaknaan 95\% (a 0,05$)$ dengan bantuan SPSS, maka diperoleh nilai Pearson Chi-Square adalah sebesar 0.008 . Berdasarkan hasil Pengujian dapat dilihat bahwa nilai $p(0,008)$ yang diperoleh lebih kecil dari $a(0,05)$. maka dapat disimpulkan bahwa ada hubungan antara pola makan dengan kejadian dispepsia di wilayah kerja Puskesmas Biak Muli Kecamatan Bambel Kabupaten Aceh Tenggara Tahun 2019.

\section{SARAN}

Karena kejadian dispepsia merupakan salah satu penyakit yang sangat berisiko dan lazim ditemukan dilingkungan masyarakat, maka responden harus memperhatikan pola makannya artinya harus mengatur jadwal makan seharihari. Disamping itu, bagi pelayanan kesehatan agar memprioritaskan program penyuluhan kesehatan bagi masyarakat pedesaan dengan materi tentang pola makan dan kejadian dispepsia. 


\section{DAFTAR PUSTAKA}

Arsyad, R.P, Irmaini D. \& Hidayaturrami. (2018). HUBUNGAN SINDROMA DISPEPSIA DENGAN PRESTASI BELAJAR PADA SISWA KELAS XI SMAN 4 BANDA ACEH. Jurnal IImiah Mahasiswa Kedokteran Biomedis. Vol, 4 (1), 36-42.

Depkes RI. (2015). Profil Kesehatan Indonesia. Jakarta.

Dinkes, Aceh. (2016). Profil Kesehatan Aceh 2016.

Fithriyana, (2018). FAKTOR-FAKTOR YANG BERHUBUNGAN DENGAN KEJADIAN DISPEPSIA PADA PASIEN DI WILAYAH KERJA PUSKESMAS BANGKINANG KOTA. Jurnal Kesehatan Masyarakat. Vol, 2(2), 4353.

Irianto, Koes. (2015). Memahami Berbagai Macam Penyakit: Penyebab, Gejala, Penularan, Pengobatan, Pemulihan dan Pencegahan. CV. Alfabeta. Bandung.

Irwan, A.T. (2015). FAKTOR RESIKO TERHADAP KEJADIAN DISPEPSIA DI INSTALASI RAWAT INAP RSUD CIDERE KABUPATEN MAJALENGKA. JOM FKp, Vol, 5(2), 823-830.

Lubis, B., \& Br.Bangun, S. (2019). FAKTOR - FAKTOR YANG BERHUBUNGAN DENGAN KEPUASAN PEMANFAATAN PENOLONG PERSALINAN PADA IBU BERSALIN DI RUMAH SAKIT GRANDMED LUBUK PAKAM. JURNAL KEBIDANAN KESTRA (JKK), 1(2), 36-43. https://doi.org/10.35451/jkk.v1i2.16 8

Muya, Y., A.W. Murni \& R.B. Herman. (2015). KARAKTERISTIK PENDERITA DISPEPSIA FUNGSIONAL YANG MENGALAMI KEKAMBUHAN DI BAGIAN ILMU PENYAKIT DALAM RSUP DR. M. DJAMIL PADANG, SUMATERA BARAT. Jurnal Kesehatan Andalas.
Vol,4(2).https://doi.org/10.25077/jka .v4.i2.p\%25p.2015.

Octaviana, E.S.L. \& K. Anam. (2018). FAKTOR-FAKTOR YANG BERHUBUNGAN DENGAN UPAYA KELUARGA DALAM PENCEGAHAN PENYAKIT DISPEPSIA DI WILAYAH KERJA PUSKESMAS MANGKATIP KABUPATEN BARITO SELATAN. JURNAL LANGSAT. Vol, 5(1).

Pardiansyah, R. \% M. Yusran. (2016). UPAYA PENGELOLAAN DISPEPSIA DENGAN PENDEKATAN PELAYANAN DOKTER KELUARGA. Jurnal Medula Unila. Vol. 5 (2).

Sembiring, I., \& Munthe, N. (2019). HUBUNGAN KOMUNIKASI TERAPEUTIK PERAWAT DENGAN KEPUASAN PASIEN RAWAT INAP. JURNAL KEPERAWATAN DAN FISIOTERAPI (JKF), 1(2), 54-61. https://doi.org/10.35451/jkf.v1i2.170

Soewadji, J. (2012). Pengantar Metodologi Penelitian. Mitra Wacana Media. Jakarta.

Sorongan, I.M, D.H.C. Pangemanan \& F.M.Untu. (2013). HUBUNGAN ANTARA POLA MAKAN DENGAN KEJADIAN SINDROMA DISPEPSIA PADA SISWA-SISWI KELAS XI DI SMA NEGERI 1 MANADO. E-Jurnal Keperawatan. Vol 1 (1).

Tiana, A., S. Susanto, I.M. Elena \& J. Hudyono. (2017). HUBUNGAN ANTARA SINDROMA DISPEPSIA DENGAN POLA MAKAN DAN JENIS KELAMIN PADA MAHASISWA FAKULTAS KEDOKTERAN UNIVERSITAS KRISTEN KRIDA WANCANA ANGKATAN 2013. J. Kedokt Meditek. Vol.23 (63).

WHO. (2015). Maternal Mortality. In : Reproduction Health And Research, Editor. Geneva : World Health Organization. 